\title{
Adaptations in the Age of Technology in Seniors
}

\author{
Stephen Foster ${ }^{1}$, Amanda Pangle ${ }^{1}$, Amy Schrader ${ }^{1}$, Jeanne Y. Wei ${ }^{1}$, Gohar Azhar ${ }^{1}$ \\ ${ }^{1}$ Department of Geriatrics, Donald W. Reynolds Institute on Aging \\ UAMS, Little Rock, Arkansas \\ azhargohar@uams.edu
}

Received Date: May 19, 2017

Accepted Date: May 26, 2017

Published Date: June 12, 2017

Abstract: The deployment of technology in today's environment has led to significant advancements in communication, socialization, and information sharing. We hypothesized that the benefits of these technologies might be underutilized in the geriatric population. Previous methods of assessing an individual's capacity for independent living relied on tools such as the Activities of Daily Living (ADL) and the Instrumental Activities of Daily Living (IADL). In recent years, with a proliferation of devices requiring technology, there exists a need for new instruments to evaluate the functional capacity of older individuals in the understanding and use of technology. We developed a structured survey to investigate the frequency of utilization of technology (cell phones, computers, blood pressure monitors, etc.) and the application and understanding of these technologies by older patients $(50-90+y r s ., n=127)$ at a geriatric out-patient university clinic. Our results indicated that while $>97 \%$ of individuals surveyed possessed a cell phone, only $83 \%$ made calls daily, with less than $55 \%$ utilizing text messaging. $83 \%$ of individuals owned a computer and only $9 \%$ lacked internet connectivity. There were several differences in the understanding and use of technological devices between the octogenarian-nonagenarian compared with younger age groups. Never the less, $75 \%$ of seniors were either interested in learning more about their cell phones and how to use the different features, or already knew how to use their cellphones. In summary, our results showed that older individuals were utilizing technology and were interested in advancing their technological skills. It is important to test the ability of older adults in their understanding and use of technology because its appropriate use can be helpful for monitoring health, security, communication and maintaining an independent lifestyle.

Keywords: technology, elderly, function, communication

\section{INTRODUCTION}

Currently, more than $13 \%$ of the US population is greater than 65 years of age [1]. Since more than $70 \%$ of those in the geriatric age group live independently, technological adaptation is essential to facilitate everyday tasks[2]. Such knowledge may support the ability to age in place, allowing the elderly to maintain their physical independence as well as maintaining a strong social life, even for those who are physically or geographically isolated [3-6]. Further more, information and communication devices (ICDs) such as cell phones, tablets, and computers, can provide methods for communication, entertainment, and lifesaving functions in emergencies. Studies have demonstrated a desire for older individuals to adopt new technologies to facilitate a safer home environment and increased physical health, as well as assist with the development of knowledge acquisition [6-8]. 
Adaptations in the Age of Technology in Seniors

In 2006, the Center for Research and Education on Aging and Technology Enhancement (CREATE) reported that older individuals were less likely to adopt ICDs than their younger peers [9]. This hesitation of the older adults in using ICDs was due in part to difficulty operating the devices and understanding the complexities of each device, including ATMs, cell phones, computers, and other devices [9-16]. However, adoption of technology by older individuals has been shown in some studies to decrease depression and improve self-esteem, particularly in individuals living alone, or for whom a physical limitation (other than old age) decreases their ability to socialize $[6,17,18]$.

Understanding the utilization of ICDs in the aging population is critical for maintaining independence in modern society. Further more, adoption of ICDs could provide additional benefits to older individuals including health monitoring, communication, intellectual stimulation and education. Here in, we explore the use of ICDs by community dwelling elderly individuals and how they interact with technology.

\section{MATERIAls ANd Methods}

\section{Participants}

This study was conducted at the Thomas and Lyon Longevity Clinic, one of the largest geriatric out patient clinics in the United States, located at the University of Arkansas for Medical Sciences (UAMS). Participation was limited to individuals over the age of 50. The study was approved by the Institutional Review Board at UAMS (IRB protocol \# 202655).

\section{Survey}

This was a cross-sectional study using a convenience sample methodology. An anonymous 51-question structured survey was designed to evaluate the personal ownership and utilization of ICDs (cell phones, tablet, computers), as well as other electronic technology (alarm systems and health monitoring devices). Geriatric patients in the waiting room of the clinic were asked if they wanted to participate in a brief anonymous survey on use of technology ( $n=127)$. If the patients agreed, they were offered either electronic or paper versions of the survey to complete. Participants either completed the survey themselves or a trained research technician read the questions and possible answers to them, and the participants indicated the answer(s) they favored.

\section{Analysis}

The survey results were analyzed with SAS software (version 9.3, SAS Institute Inc.). Categorical variables were presented as counts and percentages. Responses to questions in different age groups were compared using the standard t-test or Mann-Whitney U test and the Chi-square or Fisher's exact test, where applicable, with a cut-off p-value $<0.05$ for significance.

\section{RESULTS}

\section{Demographics}

The majority of the subjects were between 70-79 years (46\%), followed by age groups 60-69 (29\%) and 80-89 years (14\%). Those between $50-59$ years of age and $>90$ years represented $6 \%$ and $5 \%$ of the study subjects, respectively. This was a relatively well educated cohort with a significant number of the participants having an advanced degree (44\%) or at least a bachelor's degree (37\%). Individuals who only finished high school or grade school represented $14 \%$ and $4 \%$, respectively (Table 1 ). 
Adaptations in the Age of Technology in Seniors

Table1. Demographic information from survey participants. Most were in the 70-79 year old group, had attained a professional education level, and used technology every day during their career.

\begin{tabular}{|c|c|c|}
\hline \multicolumn{3}{|c|}{ Demographics } \\
\hline & $\mathbf{N}$ & $\%$ \\
\hline \multicolumn{3}{|l|}{ Age } \\
\hline $50-59$ & 8 & 6 \\
\hline $60-69$ & 37 & 29 \\
\hline $70-79$ & 58 & 46 \\
\hline $80-89$ & 18 & 14 \\
\hline $90+$ & 6 & 5 \\
\hline \multicolumn{3}{|c|}{ Highest Education Level } \\
\hline Grade School & 5 & 4 \\
\hline High School & 18 & 14 \\
\hline College & 47 & 37 \\
\hline Professional & 56 & 44 \\
\hline \multicolumn{3}{|c|}{ Use of Technology during career } \\
\hline Infrequently or never & 23 & 18 \\
\hline A few times a week & 5 & 4 \\
\hline Every day & 95 & 75 \\
\hline Did not disclose & 4 & 3 \\
\hline
\end{tabular}

\section{Significant technological device ownership exists in elderly populations}

We examined ICD ownership by survey participants of cell phones, tablets, and personal laptop/computers. We found $98 \%$ of participants owned a cell phone, including $83 \%$ of individuals over the age of 90 . High levels of ownership were also observed for personal computers and/or laptops, with $83 \%$ of participants possessing these devices. All individuals 80-89 years of age had a computer in their house, in contrast to only about $50 \%$ of individuals aged 90 or above. Conversely, tablet ownership was comparatively smaller, with only $43 \%$ of all individuals surveyed owning a tablet. There was a significant difference between ownership of a tablet between octogenarians and nonagenarians versus the other age groups ( $\mathrm{p}<0.05)$. Only $22 \%$ of $80-89$ year olds owned tablets versus $60 \%$ of participants between ages 50-59 (Figure 1). None of the participants over age 90 owned a tablet.

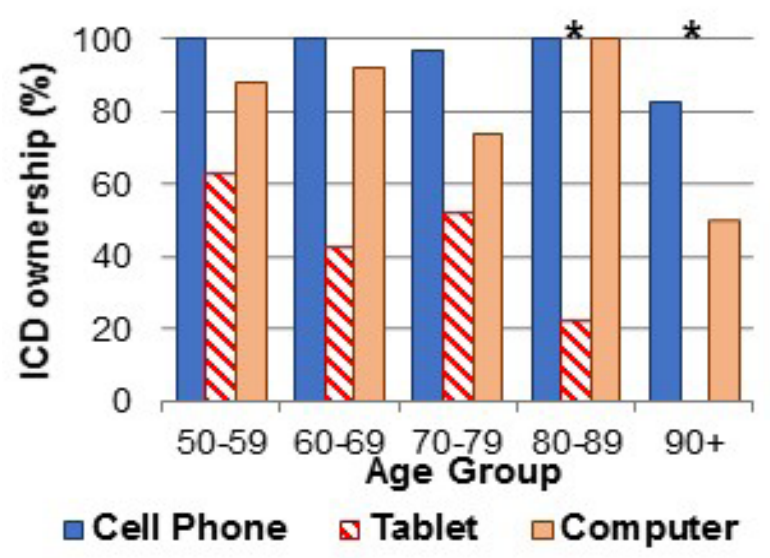

Fig1. Ownership of information and communication devices (ICDs) in the different age groups surveyed. Nearly $98 \%$ of all individuals surveyed owned a cell phone, and over $82 \%$ owned a computer, while only $43 \%$ owned a tablet. * $p<0.05$ for tablet; $<80$ years old vs $80+$ years old. 
Adaptations in the Age of Technology in Seniors

In addition to asking participants about ICDs, we also enquired about ownership of other technological devices. $100 \%$ of the 50-59 year old group owned both a GPS device and a DVD player. There was a significant difference between the age groups in the use of GPS devices, which ranged from $0-53 \%$ in the $\geq 70$ year old group vs $76-100 \%$ between ages $50-69(\mathrm{p}<0.05)$. None of those over 90 years owned a GPS device. DVD players were commonly owned by all age groups except the $90+$ year old group. Electronic medical devices, such as blood pressure machines and glucometers, were reported by $64 \%$ of the participants. The highest percentage of ownership of electronic health devices was claimed by the 50-59 year olds at 75\%, while the lowest percentage was found among the 80-89 year olds at $56 \%$ (Table 2).

Table2. DVD players and electronic medical devices were very common among nearly all of this surveyed cohort. However, for GPS devices, there was a linear inverse relationship between age and ownership. $¥$ Blood pressure machine and/or glucometer. ${ }^{*} p<0.05$ for GPS device; $<70$ years old vs $>79$ years old.

\begin{tabular}{|c|c|c|c|}
\hline Age group & GPS device (\%)* & DVD player (\%) & $\begin{array}{c}\text { Electronic medical } \\
\text { devices (\%) }^{\ddagger}\end{array}$ \\
\hline $50-59$ & 100 & 100 & 75 \\
\hline $60-69$ & 76 & 89 & 68 \\
\hline $70-79$ & 53 & 86 & 62 \\
\hline $80-89$ & 17 & 94 & 56 \\
\hline $90+$ & 0 & 0 & 67 \\
\hline
\end{tabular}

Elderly individuals are actively using cell phones.

As almost all study participants acknowledged ownership of a cell phone, we wanted to explore how often the participants used them. Participants were asked to rate their cell phones usage as "daily", weekly", or "only in case of emergency". Our results suggested a relationship between increased age and decreased cell phone usage. All individuals between $50-59$ years old used their cell phones daily, where as more than $80 \%$ of those $<80$ years old considered themselves daily users. This trend was reversed in the octogenarians and nonagenarians for "weekly" and "emergency only", which accounted for $20-22 \%$ of their calls, respectively ( $<<0.05$, Figure 2).

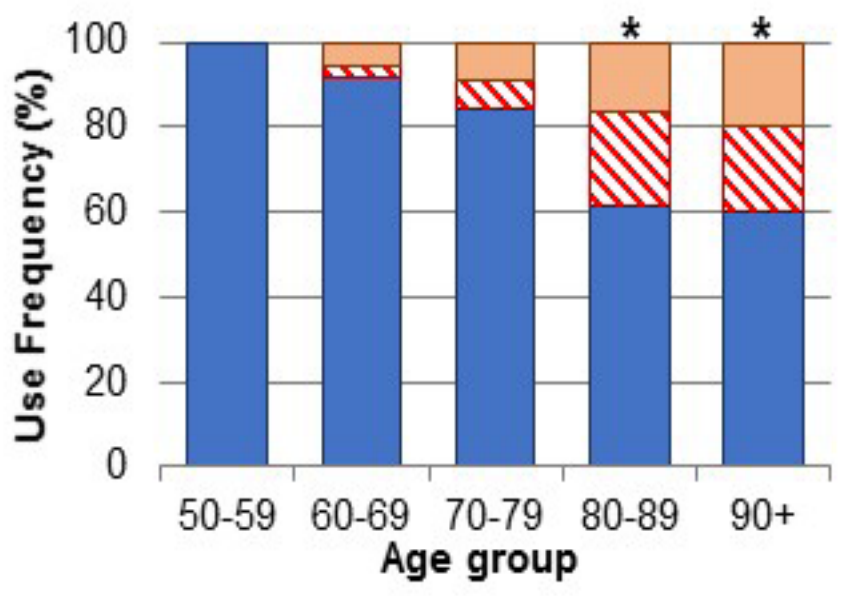

\section{aDaily $\quad$ Weekly $\quad$ Emergencies Only}

Fig2. Cell phone usage. Those who indicated that they owned a cell phone were then asked how often it was used. More than $80 \%$ of all individuals surveyed used their cell phone daily. Less than 9\% indicated that they only used the cell phone if there was an emergency. ${ }^{*} p<0.05$ for daily use; $<60$ years old vs. $80+$ years old. 
Adaptations in the Age of Technology in Seniors

Are elderly individuals sending/receiving text messages?

In order to understand how individuals were using cell phones to communicate, we investigated how often text-based communications were being sent or received. The results indicated an inverse relationship between age and sending/receiving texts. Approximately $88 \%$ of individuals $50-59$ years of age reported receiving text messages daily, and only $63 \%$ sent text messages. This trend continued downward with a significant difference in receiving or sending texts in the octogenarians and nonagenarians vs other age groups $(p<0.05$, Figure 3 ).
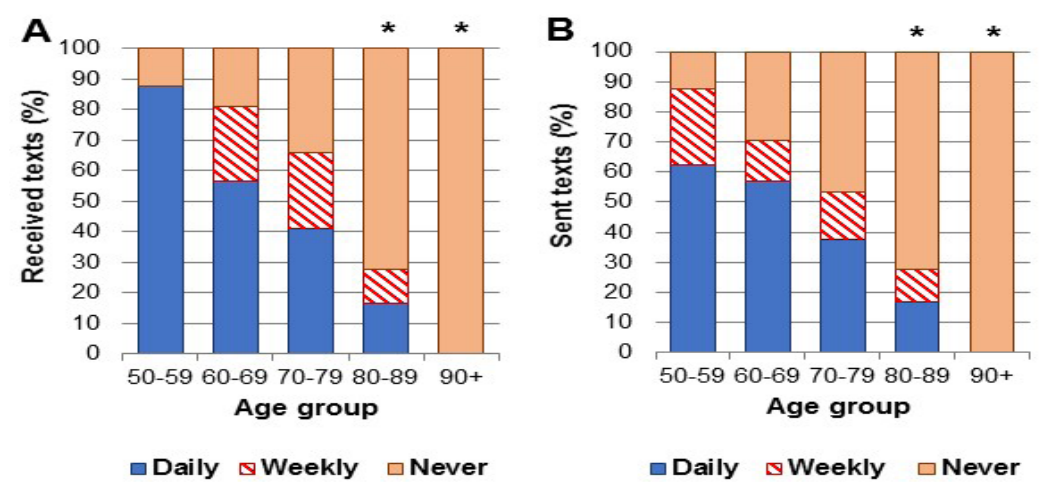

Fig3. Frequency of received and sent text messages for individuals who owned a cell phone. Over $40 \%$ of all individuals in this demographic reported either sending or receiving text messages on a daily basis. The highest prevalence of daily text messages was in the 50-59 year old group, while those 90 and over did not report having used text messaging at all. ${ }^{*} p<0.05$ for sending and receiving texts; $<80$ years old vs $80+$ years old.

\section{What type of cell phone operating systems are being utilized by the elderly?}

We wanted to understand whether elderly individuals knew the type of operating system (OS) that was installed on their cell phones. In addition to the three most common OSs (Android, iOS, and Windows), choices for "unsure", "other", and "No OS" were also provided. We discovered a preference for iOS in this population, with $32 \%$ of all participants listing this OS, including $88 \%$ of those aged $50-59$. Additionally, $15 \%$ and $9 \%$ of all participants listed Android and Windows OSs, respectively. However, increasing age was associated with a significant gap in knowledge of operating systems with $50 \%$ of octogenarians and $80 \%$ of nonagenarians being unsure about the OS in their cellphone vs other age groups ( $\mathrm{p}<0.05)$. Interestingly, $10 \%$ of all individuals listed their phone as not possessing an operating system. (Figure 4).

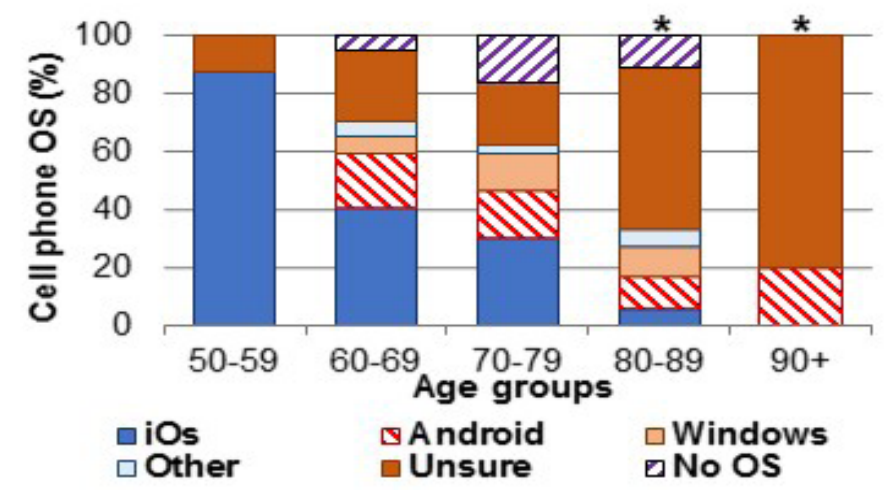

Fig4. Cell phone operating systems (OS). Participants were asked to identify what, if any, operating system their cell phone used. Only 20\% stated that they were not sure, while 69\% were not only aware that their cell phone used an OS, they were able to indicate what OS the cell phone used. * $p<0.05$ for "unsure" response; $<80$ years old vs $80+$ years old. 
Adaptations in the Age of Technology in Seniors

Are the elderly using their cell phone for non-traditional uses?

While cellphone use was listed as daily for most of the survey respondents, we wanted to find out what percent of participants used it just for phone calls or if they used applications and accessories as well. We asked respondents if they had installed applications (apps) on their cellphone, how often they used apps, and if they had ever used a Bluetooth device or a health tracker app. As with the results to most other questions, there was an inverse relationship between age and technology utilization. There was a significant difference in the age groups 70 and above in the installation and use of apps vs the under 70 age groups $(p<0.05$, Figure 5).

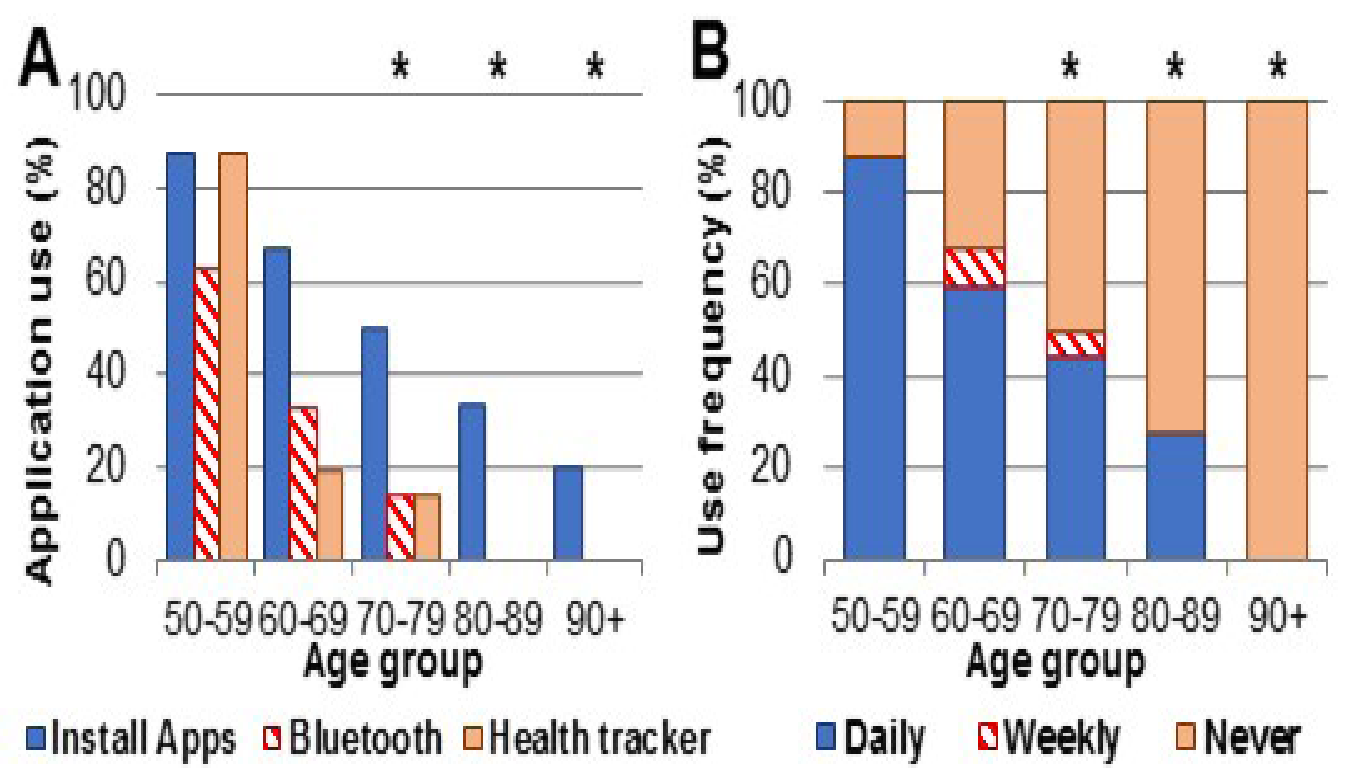

Fig5. Cell phone applications (apps), accessories, and frequency of use. A) Individuals who owned a cell phone were asked if they had ever installed an app on their cell phone, whether they had ever used Bluetooth technology, and if they had ever used an app to track their health. B) Additionally, we asked each group how often they used apps on their cell phone. Over half of those 69 years and younger had both installed an app and used it daily, while those over 90 stated that they never used apps. ${ }^{*} p<0.05$ for installation and use of apps; $<70$ years old vs $70+$ years old.

Over $87 \%$ of individuals in the $50-59$ year old group had installed applications and used them daily. In contrast, approximately $30 \%$ of those in the $80-89$ year old group had installed applications and used them daily (33\% and $28 \%$, respectively). Additionally, $88 \%$ of those in the $50-59$ year old range indicated that they use a health tracker app, and 62\% reported using a Bluetooth device, where as only $20 \%$ and $30 \%$ of $60-69$ year olds report having used a health tracker app or Bluetooth device, respectively.

\section{Are elderly individuals interested in learning how to use ICDs?}

For individuals who possessed a cellphone or other ICD, we wanted to understand whether they were interested in learning more about how to use the device. Our results indicated a moderately strong interest, with 35\% of individuals surveyed stating that they would like to learn more. However, increasing age was associated with a decreasing interest in learning about this subject with a significant difference observed between the octogenarian and nonagenarian age groups versus the younger age groups $(\mathrm{p}<0.05)$. Younger respondents, between 50-69 years (50\%), felt they already knew how to use their ICDs and were comfortable with their current knowledge. (Figure 6A). 

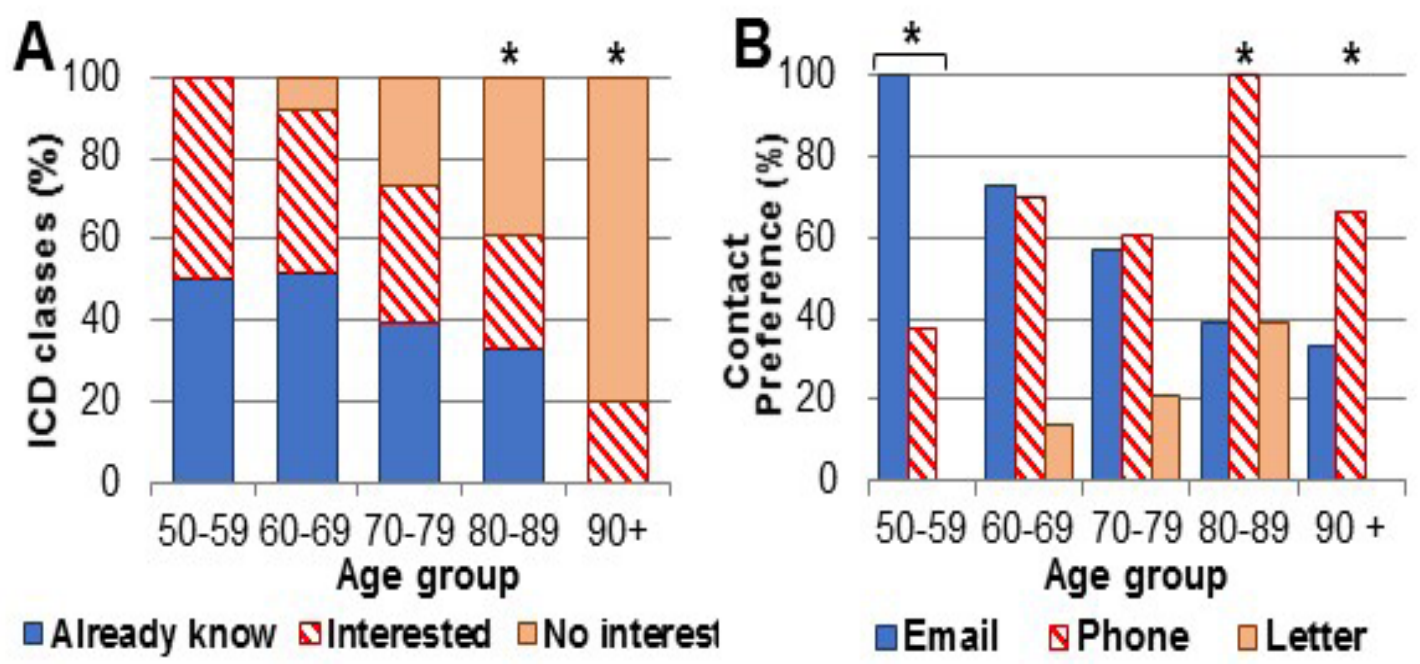

Fig6. Knowledge of ICD use and communication preference. A) Due to the common assumption that with increasing age, ICD knowledge decreases, we asked survey participants about taking classes on using modern electronics. 37\% of participants indicated that they would be interested in the classes, while $42 \%$ stated that they already knew how to use ICDs. ${ }^{*} p<0.05$ for no interest in learning; $<80$ years old vs $80+$ years old. B) We also asked participants what sort of communication methods they enjoyed using. The younger groups preferred emails to phone calls while the older groups preferred phone calls over emails. ${ }^{*} p<0.05$ for email vs phone calls; within 50-59 year old group and 50-59 years old vs $80+$ years old.

\section{How do elderly individuals like to communicate?}

We were also interested in what communication methods survey participants enjoyed using. Email was very popular in the younger age ranges, with $100 \%$ of the $50-59$ year olds, as well as $73 \%$ and $57 \%$ of those $60-69$ and 70-79 years old, respectively, choosing this response. Email was not as favored by the octogenarians, as no more than $39 \%$ selected this correspondence. Phone calls were a highly-favored communication method with every group over age 60 , including $100 \%$ of the octogenarians and more than $60 \%$ of the nonagenarians indicating that they enjoyed phone calls. However, the 50-59 year old group preferred e-mail as the mode of communication vs phone calls ( $\mathrm{p}<0.05$ Figure 6B). There were significant differences between the preferred modes of communication selected by the younger 50-59 group vs the octogenarians and nonagenarians ( $p<0.05$, Figure 6B). Interestingly, neither the youngest age group (under 60) nor the oldest (over 90) chose written correspondence (letters) as a mode of communication. Just under $20 \%$ of the participants still enjoyed receiving letters; this type of correspondence was only chosen by those 60-89 years of age.

\section{Frequency of tablet or computer use}

Study participants who possessed tablets or computers were asked how frequently they utilized those devices. We found that these devices were used almost daily across all age-groups. Moreover, computers were utilized more frequently in those $>60$ years of age (83-100\%), as compared to those $50-59$ years old (43\%). None of the participants over 90 used tablets. However, there was a significant preference for tablet use among the 50-59 age group vs the computer/laptop. ( $\mathrm{p}<0.05$, Figure 7$)$. 


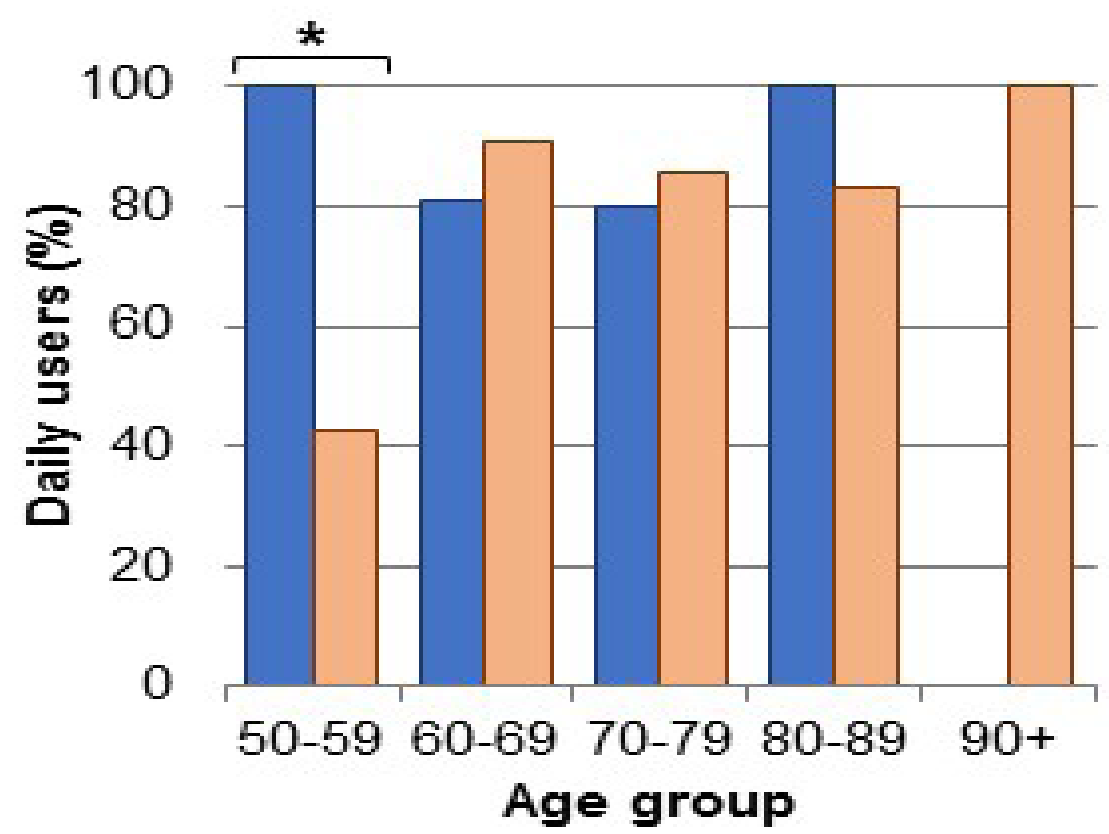

Tablet $\square$ Laptop/Computer

Fig7. Tablet and computer use. Over $80 \%$ of those who owned a tablet or computer used them daily. Daily computer use was least common for those under 60 and most common for those over 90 years of age. However, tablet ownership was highest for those under 60 and lowest for those over $90 .{ }^{*} p<0.05$ for tablet use; within 50-59 year old group.

\section{Internet connectivity and location of use}

Only $9 \%$ of individuals reported having no internet access at all. Among those with internet access, wireless access was the most common form used by $50 \%$ of all participants, followed closely by wired access at $38 \%$. $83 \%$ of all respondents accessed the internet at home, however the 80-89 year old group was the only one for which $100 \%$ reported accessing the internet at home. Use of internet at work showed an age-related decline ( $p<0.05$, Figure 8 A). Finally, approximately $11 \%$ of respondents in age groups between $50-89$ years of age listed that they had internet access via hotspot (data not shown).

\section{Reasons for using the computers or the internet}

Interestingly, the octo-nonagenarians used the internet for games approximately $60 \%$ of the time but also equally selected surfing, looking up medical records and using the computer for writing. (Figure 8B). Looking up medical records was a fairly consistent activity across all age groups (range across groups, 47-71\%). In addition, all age groups also used the computer for writing (range across groups, 43-74\%). However, individuals $<80$ tended to use the computer less for games and more for surfing the web (32 vs $92 \%, \mathrm{p}<0.05$, Figure 8B). Interestingly, $46 \%$ of all age groups also utilized their computer's electronic calendar for maintaining appointments and other reminders (data not shown). 


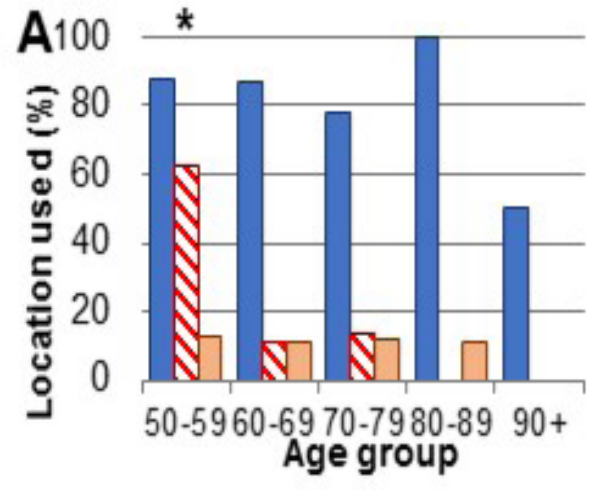

口Home $\quad$ Work $\square$ Other

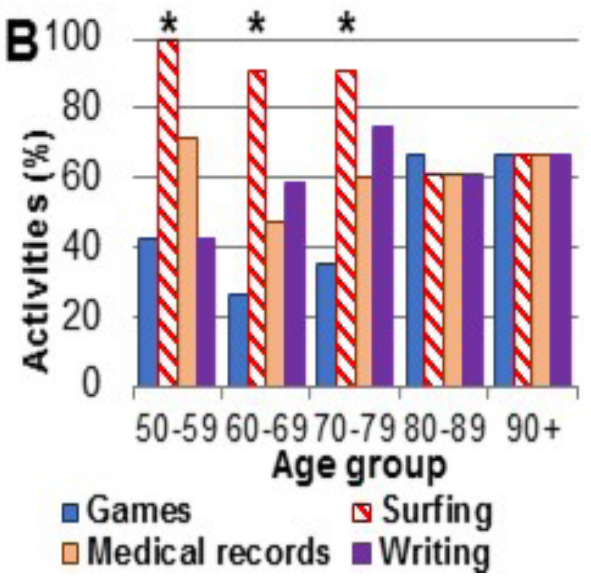

Fig8. Location of internet use and type of computer activities. A) Survey participants were asked for all of the places where they regularly accessed the internet. 50\% or more of participants in all age groups stated that they accessed the internet at home, while those under 80 years of age were the only age groups to indicate that they ever accessed internet at work. ${ }^{*} p<0.05$ for internet access at work; $<60$ years old vs $80+$ years old. B) Participants were then asked for what activities they used the computer. Surfing the internet was the most, and playing games the least, reported activity for all but the oldest age group. ${ }^{*} p<0.05$ for surfing the web; $<80$ years old vs $80+$ years old.

\section{Discussion}

The aim of this study was to assess how older individuals interacted with technology. Our results support a growing body of evidence demonstrating an increased adoption of ICDs by older individuals. With numerous studies demonstrating the benefits in health, socialization, improvement in depression, and integration into modern society, the continued adoption of modern technologies is exciting.

Several interesting findings emerged from this study. Although this research was conducted at a university hospital located in the largest city in the state, Arkansas is largely an agricultural state. Many people come from rural communities, and career opportunities within the state tend not to be technologically-related office work. Additionally, Arkansas ranks $6^{\text {th }}$ lowest in computer ownership in the nation, and $2^{\text {nd }}$ lowest for high speed internet accessibility [19]. As such, we did not expect to see such a high usage of ICDs and other devices in our population of community-dwelling elderly. Technology acceptance is usually only seen at high levels among populations for whom modern technology is common-place in everyday life as they age, or if the particular population being surveyed has a higher level of education [5, 20-22]. In this instance, our population of older adults is unique, as over $80 \%$ of our participants had a college or post-graduate degree, and $75 \%$ had used technology every day during their careers (Table1). We believe that the impact of education on technology acceptance is also reflected in the results described in our manuscript.

Cellphone ownership and daily utilization were reported at high levels, even in octo-nonagenarians, although these older participants were not that familiar with alternative communication methods, such as texting. Nearly $80 \%$ of those over 80 years old stated that they had never sent nor received texts, whereas over $80 \%$ of those 50-59 years of age sent and received texts on a regular basis. This might reflect the emergence of long-distance communication as commonplace only during the last two-three decades, which would still have been in the later phase of life for the older age groups [20]. When we combined the octogenarians with the nonagenarians, we observed significant differences between the octo-nonagenarian group versus the younger age groups in most of the questions surveyed. Interestingly, a significant majority of participants in the 50-79 year old range indicated that they were able to recognize the OS of their cell phone. However, while we assume accuracy in the 
selection of an operating system, it is entirely possible individuals were incorrect in their selection. Although the younger cohort ( $<70$ years) admitted knowing how to install and utilize apps, it is unclear how proficient they were. Approximately half of the octo-nonagenarians expressed little or no interest in learning more about other technologies and indicated phone calls were their preferred mode of communication. For those in the upper age ranges in our study, part of the reason they didnot utilize new technologies might also have been due to how they perceived these technologies [23, 24]. Many types of ICDs currently marketed concentrate on technical capacity of the device and often overlook the potential opportunities they may offer in terms of communication and entertainment $[24,25]$. In our own study, the octo-nonagenarian group indicated a higher usage of the computer for games compared with the younger group. Hence, we need to redesign devices that will capture the interest and serve the needs of the aging population. Computer games could potentially also provide various forms of training or provide shared personal experiences that could assist in enhancing mood or cognition $[6,24,26]$.

Nearly all age groups showed a high frequency of daily usage of both the computer and tablet. However, those $<60$ years showed a preference for the tablet over the computer, while all those over the age of 90 exclusively used computers (as none of them owned a tablet). Prevalence of tablet use will probably increase as the younger cohort ages due to development of smaller, lighter, and more portable tablets [20]. In all age groups, the most popular activity overall was surfing the internet, however, for those $80+$ years of age, activity choice was more evenly distributed between surfing, games, writing and accessing medical information. These findings were rather unexpected, although it may be explained by the higher educational background of the patients who chose to participate in the survey.

As technology becomes ever more portable, convenient, user-friendly, and economical, the hesitation for technological adoption will hopefully become less in the older age groups. It is also quite likely that the trends in the use of technology will change in the next decade to include more wearable technology that will be adopted by facilities taking care of older individuals as well as individuals at home in the geriatric age-groups [27, 28]. Our study subjects were predominantly Caucasian (non-Hispanic). However, cultural influence, in addition to personal experiences, must be considered when examining technology acceptance, or proposing technology training $[16,23,26,29]$. Age or gender bias within a culture can also influence the delayed acceptance of technology $[26,30]$. Training focused on technical capabilities of ICDs might not appeal to all cultural groups, while training that focuses on specific personal or social needs (i.e. maintaining familial relationships or caregiving tips), might significantly interest a subset of the population to adopt these technologies [26]. A number of programs to aid cognition are being developed and although none have demonstrated consistent results so far, it is a promising area of research [31]. In addition, focusing on the social capabilities of technology may empower the older population by providing them opportunities to connect across many generations, take part in different interest groups, provide input, receive appreciation, make friends and reduce the sense of isolation [30, 32].

This study explored the utilization of technologies in a small population of community-dwelling elderly and found a higher degree of utilization and proficiency than expected. The use of text-based communications by older individuals demonstrates the adoption of traditional technology (phone) with modern developments (text-based communications). Further more, the adoption of other devices, including tablets, computers, and laptops, coupled with over $90 \%$ of respondents having access to the internet, imply the use of these devices for communication and networking.

Since the population is aging, businesses have been interested in marketing ICDs to the older population, especially octogenarians and nonagenarians. Many businesses and areas of active research are trying to develop more user-friendly and enjoyable programs to encourage the older population to adopt new technologies at an ever-increasing pace, thus allowing this population to remain independent for a significantly longer period 
of their life $[8,25,29,33]$. Such technologies include advanced programs that learn from the user himself/ herself, adapting the interface to suit the user. For the elderly, several areas of research have identified a need for including greater social abilities in the programs, both by allowing other users of similar age to interact, as well as allowing individuals to verbally and gesturally interact with the programing $[3,23,32,33]$. This may encourage faster adoption of ICDs in this population by permitting them to comfortably communicate in a wellknown manner with new technologies.

While promising, the study had a number of limitations. In general, our study participants were urban city dwelling and relatively well educated individuals attending an out-patient geriatric clinic. Hence our findings cannot be extrapolated to those with lower educational attainment or to rural populations. The survey also lacked complete demographic information and it would be important in the future to assess technological competence and preferences based on gender, ethnicity, or socioeconomic background. Never the less, in this report, we have provided for the first time insight into the use of technology by adults over the age of 50 years. Our data suggest ICD use is widely adopted and successfully used by a subset of educated older adults, including octo-nonagenarians, in different spheres of their lives. Hence technology could be leveraged to educate and provide better care for the rapidly growing aging population.

\section{CONCLUSIONS}

This research has demonstrated continued adoption and integration of modern technology into the daily lives of older individuals. Therefore, in addition to assessing the physical function of geriatric patients with ADLs and IADLS, we should also incorporate evaluation of their functional technological skills. Now a days, the number of technological devices being used for communication and health monitoring are increasing exponentially. As health care providers, we need to encourage the development of better programs to enhance the technological knowledge of older adults with an aim towards enhancing their function and improving their quality of life.

\section{ACKNOWLEDGMENTS}

This study was supported in part by the Claude D. Pepper Older American Independence Center grant, National Institute on Aging (1P30AG28718) awarded to University of Arkansas for Medical Sciences. We thank Laura Gocio for her assistance with manuscript preparation.

\section{REFERENCES}

1. Azhar G, Wei JY. The Demographics of Aging and Its Impact on the Cardiovascular Health. Curr Cardiovasc Risk Rep 2015; 9(4): 1-6.

2. Ortman JM, Velkoff VA, Hogan H. An aging nation: the older population in the United States. Washington, DC: US Census Bureau. 2014; 25-1140. (pdf accessed 05/11/2016).

3. Beer JM, Mitzner TL, Stuck RE, Rogers WA. Design Considerations for Technology Interventions to Support Social and Physical Wellness for Older Adults with Disability. Int. J. Autom. Smart Technol. 2015; 5(4):249-64.

4. Bobillier Chaumon ME, Michel C, Tarpin Bernard F, Croisile B. Can ICT improve the quality of life of elderly adults living in residential home care units? From actual impacts to hidden artefacts. BEHAV INFORM TECHNOL. 2014; 33(6):574-90.

5. Saboor M, Sum S, Sahaf R, Pourghasem M. The Internet UseIn Elderly People. Med Glas/Med Gaz. 2015; 20(56).

6. Sánchez-Valle M, Abad MV, Llorente-Barroso C. Empowering the Elderly and Promoting Active Ageing Through the Internet: The Benefit of e-inclusion Programmes. InSafe at Home with Assistive Technology 2017 (pp. 95-108). Springer International Publishing. 
Adaptations in the Age of Technology in Seniors

7. Barrett LL. Healthy@ home. Washington, DC: AARP Foundation; 2008 Mar.

8. Mynatt ED, Melenhorst AS, Fisk AD, Rogers WA. Aware technologies for aging in place: understanding user needs and attitudes. IEEE Pervasive Comput. 2004; 3(2): 36-41.

9. Czaja SJ, Charness N, Fisk AD, Hertzog C, Nair SN, Rogers WA, Sharit J. Factors predicting the use of technology: findings from the Center for Research and Education on Aging and Technology Enhancement (CREATE). Psychol Aging. 2006; 21(2): 333.

10. Charness N, Schumann CE, Boritz GM. Training older adults in word processing: Effects of age, training technique, and computer anxiety. Int J Technol Aging. 1992; 5(1): 79-106.

11. Czaja SJ, Sharit J. Performance of a complex computer-based trouble shooting task in the bank industry. Int J Cognitive Ergon Hum Factor. 1999; 3: 1-22.

12. Czaja SJ, Sharit J, Ownby R, Roth DL, Nair S. Examining age differences in performance of a complex information search and retrieval task. Psychol Aging. 2001; 16(4): 564.

13. Rogers WA, Fisk AD, Mead SE, Walker N, Cabrera EF. Training older adults to use automatic teller machines. Hum Factor. 1996; 38(3): 425-33.

14. Sharit J, Czaja SJ, Nair S, Lee CC. Effects of age, speech rate, and environmental support in using telephone voice menu systems. Hum Factors: J Hum Factor Ergon Soc. 2003; 45(2): 234-51.

15. Rainie L, Horrigan J. Internet: The main streaming of online life. Pew Internet and American Life Project. Trends. 2005; 56-69.

16. Kwong YH. Digital divide: Computer and internet use by elderly people in Hong Kong. Asian J Gerontol Geriat. 2015; 10(1): 5-9.

17. Cotten SR, Ford G, Ford S, Hale TM. Internet use and depression among retired older adults in the United States: A longitudinal analysis. J GERONTOL B-PSYCHOL. 2014; 69(5): 763-71.

18. Elliot AJ, Mooney CJ, Douthit KZ, Lynch MF. Predictors of older adults' technology use and its relationship to depressive symptoms and well-being. J GERONTOL B-PSYCHOL. 2014; 69(5):667-77.

19. File T, Ryan C. Computer and Internet use in the United States: 2013. American Community Survey Reports. 2014 Nov. (pdf accessed 5/15/2017)

20. Heerink M, Kröse B, Evers V, Wielinga BJ. The influence of social presence on acceptance of a companion robot by older people. J Phys Ag. 2008; 2(2): 33-40.

21. Saied A, Sherry SJ, Castricone DJ, Perry KM, Katz SC, Somasundar P. Age-related trends in utilization of the internet and electronic communication devices for coordination of cancer care in elderly patients. J GeriatrOncol. 2014; 5(2): 185-9.

22. Thygesen E, Leifson RM, Martinez S. Mapping Elderly Citizen's Computer and ICT Use in a Small-sized Norwegian Municipality. In HEALTHINF 2015 (pp. 131-142).

23. Chen K, Chan AH. Use or non-use of gerontechnology - a qualitative study. Int J Environ Res Publ Health. 2013; 10(10):4645-66.

24. Niehaves B, Plattfaut R. Internet adoption by the elderly: employing IS technology acceptance theories for understanding the age-related digital divide. Eur J Inf Syst. 2014; 23(6):708-26. 
Adaptations in the Age of Technology in Seniors

25. Dogruel L, Joeckel S, Bowman ND. The use and acceptance of new media entertainment technology by elderly users: development of an expanded technology acceptance model. Behav Inform Technol. 2015; 34(11): 1052-63.

26. Padilla-Góngora D, López-Liria R, del PilarDíaz-López M, Aguilar-Parra JM, Vargas-Muñoz ME, Rocamora-Pérez P. Habits of the Elderly Regarding Access to the New Information and Communication Technologies. ProcediaSocBehav Sci. 2017; 237:1412-7.

27. Park S, Jayaraman S. Enhancing the quality of life through wearable technology. IEEE Eng Med BiolMag. 2003; 22(3): 41-8.

28. Pigini L, Bovi G, Panzarino C, Gower V, Ferratini M, Andreoni G, Sassi R, Rivolta MW, Ferrarin M. Pilot test of a new personal health system integrating environmental and wearable sensors for telemonitoring and care of elderly people at home (SMARTA project). Gerontol. 2017; 63(3): 281-6.

29. Huang LY, Lee CF. A Preliminary Exploration of Technology Necessities Among Elderly Living Alone. In International Conference on Human Aspects of IT for the Aged Population. 2016 (pp. 23-31). Springer International Publishing.

30. Bardhan A, Bandyopadhyay S, Mandal KS. Redefining the role of elderly as facilitator to educate young generation through Information and Communication Technology. In International Conference on Ageing Well-Social and Managerial Challenges (ICAW) held in Kochi, Kerala 2014.

31. Shah TM, Weinborn M, Verdile G, Sohrabi HR, Martins RN. Enhancing cognitive functioning in healthly older adults: a systematic review of the clinical significance of commercially available computerized cognitive training in preventing cognitive decline. NeuropsycholRev. 2017:1-9.

32. Shih HL, Huang FT, Lin TG, Lee CT. INVITATION: An Elderly Friendly ICT-enabled Interactive Installation to Promote Social Participations. Int J Autom Smart Technol. 2015; 5(4): 225-31.

33. Williams D, Alam MA, Ahamed SI, Chu W. Considerations in designing human-computer interfaces for elderly people. InQuality Software (QSIC), 2013 13th International Conference on 2013 Jul 29 (pp. 372-377). IEEE.

Citation: Stephen Foster, Amanda Pangle, Amy Schrader, Jeanne Y. Wei, Gohar Azhar, "Adaptations in the Age of Technology in Seniors". American Research Journal of Geriatrics and Aging; V1, I1; pp:1-13.

Copyright (C) 2017 Stephen Foster, Amanda Pangle, Amy Schrader, Jeanne Y. Wei, Gohar Azhar, This is an open access article distributed under the Creative Commons Attribution License, which permits unrestricted use, distribution, and reproduction in any medium, provided the original work is properly cited. 